\title{
Intrathecal Meperidine Plus Lidocaine for Prevention of Shivering during Cesarean Section
}

\begin{abstract}
Departments of Anaeasthesiology, ${ }^{\star}$ Student Research Committee, Jahrom University of Medical Sciences, Jahrom,
${ }^{\dagger}$ Department of Obstetrics and Gynecology, Shiraz University of Medical Sciences, Shiraz, Iran
\end{abstract}

\begin{abstract}
Ahmad Rastegarian, MD, Mohamed Amin Ghobadifar, MD*, Hossein Kargar, MD*, and Zahra Mosallanezhad, $\mathrm{MD}^{\dagger}$
\end{abstract}

\section{Background:}

Shivering related to spinal anesthesia may interfere with monitoring and is uncomfortable. The aim of the present study was to investigate low-dose intrathecal meperidine for the prevention of shivering after induction of spinal anesthesia in parturients with cesarean section.

\section{Methods:}

This was a prospective randomized, double-blind, placebo-controlled trial including 100 parturients, of American Society of Anesthesiologists (ASA) physical status I or II, scheduled for elective cesarean section under spinal anesthesia who were randomly assigned to a meperidine $(0.2 \mathrm{mg} / \mathrm{kg})$ plus hyperbaric lidocaine $(5 \%, 75 \mathrm{mg}, \mathrm{n}=50$; group $\mathrm{M})$ group or a placebo plus hyperbaric lidocaine $(5 \%, 75 \mathrm{mg}, \mathrm{n}=50$; group $\mathrm{L})$ group. Demographic and surgical data, adverse events, and the mean intensity for each parturient were assessed during the entire study period by a blinded observer.

\section{Results:}

There were no significant differences between the two study groups regarding the demographic and surgical data $(P>0.05)$. The incidence of shivering during the entire study period significantly decreased in the group of parturients who received intrathecal meperidine $(P=0.04)$. There were no significant differences in nausea and vomiting between the two groups.

\section{Conclusions:}

Low-dose intrathecal meperidine $(10 \mathrm{mg})$ is safe and effective in reducing the incidence and severity of shivering associated with spinal anesthesia in parturients with cesarean section. (Korean J Pain 2013; 26: 379-386)

\section{Key Words:}

cesarean, intrathecal meperidine, shivering, spinal anesthesia.

Received August 5, 2013. Revised September 18, 2013. Accepted September 25, 2013.

Correspondence to: Mohamed Amin Ghobadifar, MD

Department of Student Research Committee, Medicine School, Jahrom University of Medical Sciences, Motahari Avenue, Jahrom, Iran Tel: +98-936-620-8078, Fax: +98-711-636-13-86, E-mail: amin_m505@yahoo.com

() This is an open-access article distributed under the terms of the Creative Commons Attribution Non-Commercial License (http:// creativecommons.org/licenses/by-nc/3.0/), which permits unrestricted non-commercial use, distribution, and reproduction in any medium, provided the original work is properly cited.

Copyright (C) The Korean Pain Society, 2013 


\section{INTRODUCTION}

Peri- and intra-operative shivering induces patient discomfort due to severe muscle movements, and it also causes tachycardia and hypertension. This eventually leads to increased carbon dioxide synthesis and increased oxygen consumption, which results in an increased cardiac workload and pulmonary ventilation capacity. It also leads to an increase in the metabolic rate by up to $400 \%$ [1].

Spinal anesthesia can be quickly and simply induced, and due to its fewer systemic complications, it is more advantageous than general anesthesia. Likewise, spinal anesthesia is vastly used for cesarean section $[2,3]$. In spinal anesthesia for cesarean section, the anesthetized area (the sympathetic nerve innervated in the lower limbs) is blocked. From the center of the body to the periphery, this blockage redistributes the body heat. Hence, the afferent temperature signal in the anesthetized area is not transmitted to thermoregulation center which is located in the hypothalamus. This leads to a disruption in normal temperature regulation, resulting in increased shivering and a decreased core temperature $[4,5]$. Shivering related to spinal anesthesia is a frequent complication, and the median incidence of shivering associated with neuraxial anesthesia is reported to be as high as 56\% [6]. Those effects are principally bothersome in an obstetrical population [7]. Therefore, it is important to prevent the incidence of shivering during spinal anesthesia.

Intravenous administration of drugs including magnesium sulfate, clonidine, meperidine, physostigmine, and ketanserin has been suggested for the treatment of shivering $[8,9]$. Of these, meperidine seems to be the most effective agent for the treatment of shivering [10]. Meperidine is a $\kappa$ (Kappa)-receptor agonist and opioid $\mu(\mathrm{Mu})$-receptor that reduces the threshold of vascular constriction which is known to effectively treat shivering [11].

During last decade, some studies have reported the positive effects of different doses of intrathecal meperidine during spinal anesthesia on reducing the severity and incidence of perioperative shivering [12-14]. Intravenous meperidine is widely used for the treatment of shivering intraoperatively (during the cesarean section) and postoperatively (in the recovery room) but it could be associated with side effects. In addition, use of high doses of intrathecal meperidine may have similar side effects such as nausea, vomiting, respiratory distress and pruritus. Adding meperidine to the intrathecal hyperbaric bupivacaine fusion during spinal anesthesia reduces the incidence and severity of shivering shown in obstetrical populations undergoing cesarean delivery $[15,16]$.

Different doses of intrathecal meperidine have been used to prevent shivering during spinal anesthesia [14,15,17]. However, there is a consensus concerning the optimal dose. Given this background, with a local anesthetic, we administered an intrathecal infusion of low dose meperidine for spinal anesthesia in women who were undergoing cesarean section. Then, we evaluated the effects of this type of treatment on the inhibition of shivering in patients during spinal anesthesia.

\section{MATERIALS AND METHODS}

This study was performed at the anesthetic clinic of Peymanie hospital, a tertiary health center affiliated with Jahrom University of Medical Sciences. We enrolled 100 parturients (ASA physical status I or II) who were scheduled for elective cesarean delivery under spinal anesthesia ranging in age from 18-40 years between April and December of 2012 (Fig. 1). The review board of Jahrom University of Medical Sciences approved the study protocol and all the enrolled parturients completed an informed consent form. None of the patients had a history of contraindication to spinal anesthesia and cesarean section surgery, sever preeclampsia, hypo or hyperthyroidism, Reynaud's syndrome, preoperative body temperature > $38^{\circ} \mathrm{C}$, a height $<152 \mathrm{~cm}$, and allergies to the study medications (meperidine and lidocaine).

Parturients were given a sealed envelope that included their admission number by an assistant who was blinded to the study. This admission number was the participant's medical chart number. A physician who was blinded to the study opened the envelopes in the order of presentation and gave the parturients a black box if they had an even number and a white box if they had an odd number. The participants with odd numbers $(n=50)$ were assigned to the $5 \%$ mepridine $0.2 \mathrm{ml}$ (Pethidine ${ }^{\circledR}$, Hana Pharmaceutical Corp, Korea; no preservative) $(0.2 \mathrm{mg} / \mathrm{kg})$ plus hyperbaric lidocaine (Actavis, Zug, Switzerland) (5\%, 75 mg, n = 50; group M) group and those with even numbers $(n=50)$ were assigned to the equivalent volume of placebo (sterile saline) plus hyperbaric lidocaine ( $5 \%, 75 \mathrm{mg}, \mathrm{n}=50$; group L) 


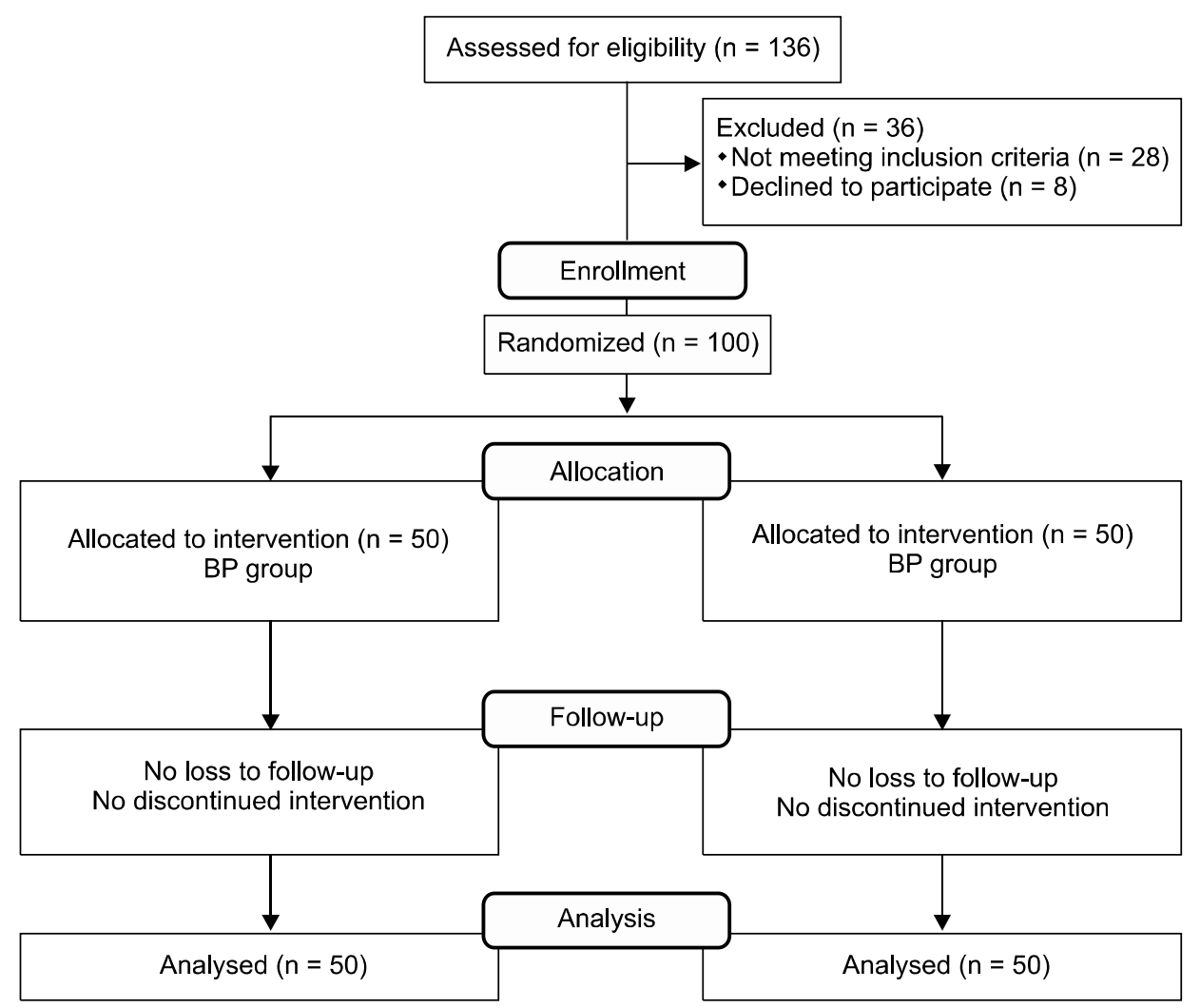

Fig. 1. Participation flow chart.

group. Before performing spinal anesthesia, patients were monitored for blood pressure (BP), heart rate (HR), electrocardiogram, and oxygen saturation, and received intravenous warmed $\left(37^{\circ} \mathrm{C}\right)$ lactated Ringer's solution $10 \mathrm{ml} / \mathrm{kg}$ Through a Hudson mask, oxygen was given during anesthesia, and parturients were covered with a layer of surgical drapes over the clavicles, chest and thighs but not actively warmed. An anesthesiologist who was blinded to the study performed the spinal block. With a 25-G Quincke needle in the sitting position at the inter space of L3-L4, spinal anesthesia was performed. After spinal injection, patients were placed in the supine position with a left lateral tilt.

TO was determined as the time at the end of the injection. By using pinpricks, the sensory block was evaluated every $5 \mathrm{~min}$ during the first $40 \mathrm{~min}$ and then every 10 min thereafter. The level of segment blocked was evaluated during operation and in the post-anesthesia care unit (PACU). A blinded trained anesthesiology resident evaluated the grades of shivering intensity [18] every $5 \mathrm{~min}$ during the intra- and post-operative periods: 0 , no shivering; 1, peripheral, piloerection vasoconstriction, or both are present but no visible shivering; 2 , muscular activity in only one muscle group; 3, muscular activity in more than one muscle group but no generalized shivering (moderate muscular activity); 4, shivering involving the whole body (violent muscular activity). To prevent unwanted complications in the mother and fetus, shivering was stopped with IV clonidine $(0.5 \mu \mathrm{g} / \mathrm{kg})$ after evaluating the shivering intensity in both groups.

Systolic and diastolic BP and HR were measured before, immediately after, and at 5, 15,30, and 60 minutes after spinal anesthesia. Simultaneously, while recording the shivering intensity, a blinded observer recorded the peripheral and core temperature, peripheral oxygen saturation, and intrathecal opioid-related side effects. Arterial hypotension was defined as a decrease in systolic blood pressure $<90 \mathrm{mmHg}$ or less than $25 \%$ of the baseline value. Hypotension and HR $<50$ were treated with intravenous ephedrine $5 \mathrm{mg}$ and intravenous atropine $0.5 \mathrm{mg}$, respectively. If nausea, vomiting, and pruritus occurred during the operation and in the PACU, they were noted. We administered intravenous metoclopramide $10 \mathrm{mg}$ in $\mathrm{pa}-$ tients with nausea and vomiting during or after spinal anesthesia. Respiratory depression ( $\mathrm{SpO} 2$ less than 95\%) was supported with active ventilation in both groups. Apgar 
Table 1. The Demographic and Surgery Data During the Whole Time of the Study Period (Data Are Expressed as Mean \pm SD)

\begin{tabular}{lccc}
\multicolumn{1}{c}{ Variable } & Group $L^{*}(n=50)$ & Group $M^{*}(n=50)$ & $P$ value \\
Age (years) & $26.3 \pm 3.7$ & $27.0 \pm 6.1$ & 0.18 \\
BMI $\left(\mathrm{kg} / \mathrm{cm}^{2}\right)$ & $23.3 \pm 1.5$ & $22.8 \pm 2.0$ & 0.14 \\
Heart rate (beats per min) & $86.1 \pm 13.1$ & $88.2 \pm 11.9$ & 0.40 \\
SBP (mmHg) & $122.7 \pm 9.2$ & $121.1 \pm 12.0$ & 0.46 \\
DBP (mmHg) & $78.4 \pm 8.9$ & $79.1 \pm 11.2$ & 0.73 \\
Peripheral oxygen saturation & $98.9 \pm 1.0$ & $99.0 \pm 0.8$ & 0.45 \\
Core temperature & $37.0 \pm 0.3$ & $37.0 \pm 0.3$ & 0.63 \\
Lowest core temperature & $36.4 \pm 0.3$ & $36.5 \pm 0.5$ & 0.16 \\
Lowest peripheral temperature & $33.9 \pm 0.8$ & $34.0 \pm 0.9$ & 0.33 \\
Surgery duration (min) & $60.1 \pm 7.8$ & $59.3 \pm 8.6$ & 0.62 \\
Time to reach highest block (min) & $14.7 \pm 4.0$ & $12.3 \pm 5.3$ & 0.01 \\
Sensory level; median (range) & $T 6(T 3$ to T7) & & \\
Apgar & $8.5 \pm 0.2$ & $8.6 \pm 0.2$ & 0.20 \\
$\quad 1$ min & $9.7 \pm 0.1$ & $9.5 \pm 0.1$ & 0.34 \\
5 min &
\end{tabular}

BMI: body mass index, SBP: systemic blood pressure, DBP: diastolic blood pressure. ${ }^{\star} \mathrm{L}$ : control group, M: case group.

.scores at 1 and 5 minutes and surgery duration were also recorded by a blinded observer.

Based on the preliminary study, a power analysis was done to find a sufficient sample size in determining a significant difference in the intensity of shivering by using an alpha value of 0.05 and a power of $80 \%$. The intensity of shivering was $65 \%$ in the meperidine group and $25 \%$ in the control in the preliminary study. This established that a sample size of twenty four patients was adequate per group. We enrolled 50 parturients in each group to compensate for possible none valuable data. The Statistical Package for Social Science (SPSS) for Windows, version 14 (SPSS Inc., Chicago, IL) was used for data analysis. Paired T-tests were used to compare results within the groups; independent $\mathrm{T}$-tests were used to compare results between the groups; $\mathrm{X}^{2}$ tests were used to compare proportions. Data are reported as the means $\pm \mathrm{SD}$ for $95 \%$ confidence interval (CI) with $5 \%$ degree of freedom. A two-sided $P$ value $<0.05$ was considered statistically significant.

\section{RESULTS}

All of the participants successfully finished the study. According to Table 1, the time to reach the highest block in the meperidine group was significantly lower than that of the controls $(P=0.01)$. There were no significant differences in vital signs between the two groups during the entire study period. The demographic and surgical data of the

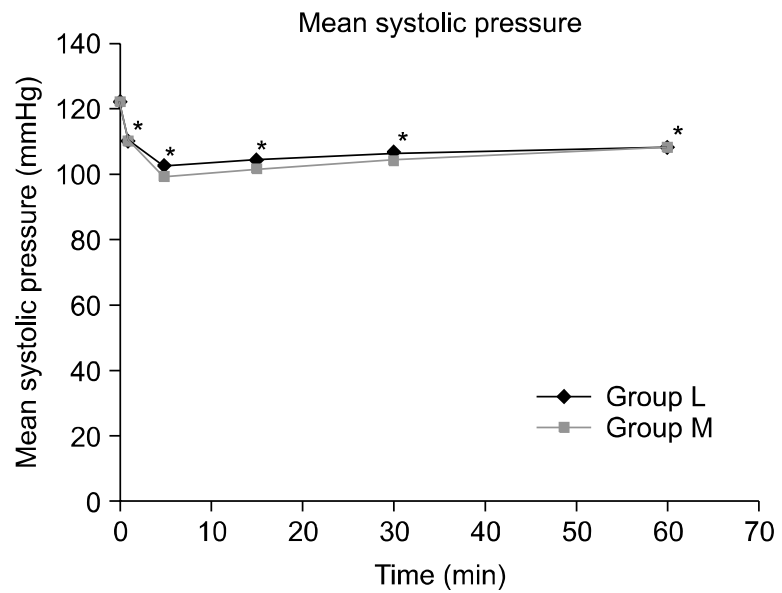

Fig. 2. Changes in mean systolic pressure between groups $\mathrm{L}$ and $M$. Each bar represents the mean $\pm S D$. Group $L(n$ $=50$ ) received spinal anesthesia that consisted of hyperbaric lidocaine $(5 \%, 75 \mathrm{mg})$ and normal saline. Group M $(n=50)$ received spinal anesthesia that consisted of hyperbaric lidocaine $(5 \%, 75 \mathrm{mg})$ and meperidine $(0.2 \mathrm{mg} / \mathrm{kg})$. There were no significant differences between group $L$ and $M$. ${ }^{\star} P<0.05$ : Compared to pre-operative values within each group.

2 study groups are presented in Table 1. All baseline measurements were comparable between the two groups.

The mean systolic pressure was $121.0 \pm 14.6$ in the $\mathrm{L}$ group and $121.8 \pm 11.5$ in the $\mathrm{M}$ group, prior to spinal anesthesia; nevertheless, the systolic pressure immediate after and at 5, 15, 30, and 60 minutes after the spinal 
anesthesia significantly decreased compared to the baseline in the 2 study groups $(P<0.05)$ (Fig. 2). Prior to spinal anesthesia, the mean diastolic pressure was $80.7 \pm$ 9.5 in the L group and $80.5 \pm 7.2$ in the M group; never-

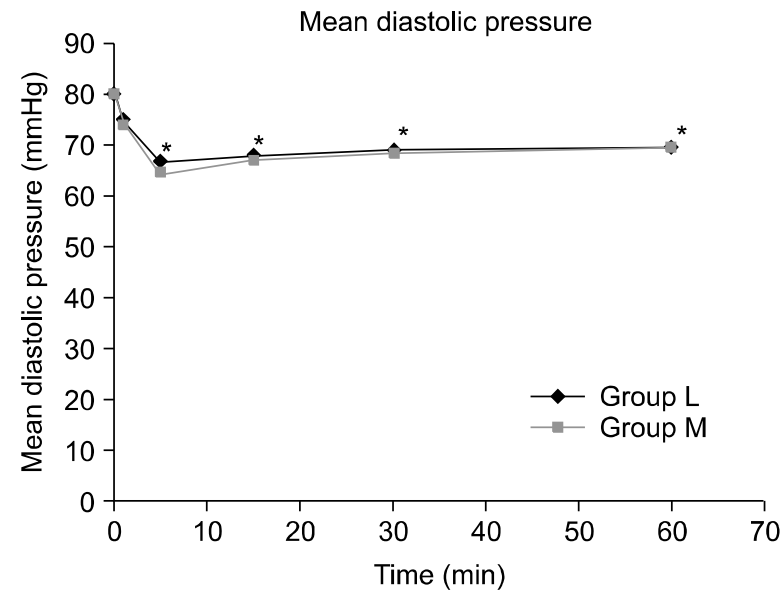

Fig. 3. Changes in mean diastolic pressure between groups $L$ and $M$. Each bar represents the mean \pm SD. Group $L$ (n $=50$ ) received spinal anesthesia that consisted of hyperbaric lidocaine $(5 \%, 75 \mathrm{mg})$ and normal saline. Group M $(n=50)$ received spinal anesthesia that consisted of hyperbaric lidocaine $(5 \%, 75 \mathrm{mg})$ and meperidine $(0.2 \mathrm{mg} / \mathrm{kg})$. There were no significant differences between group $L$ and $M$. ${ }^{\star} P<0.05$ : Compared to pre-operative values within each group.

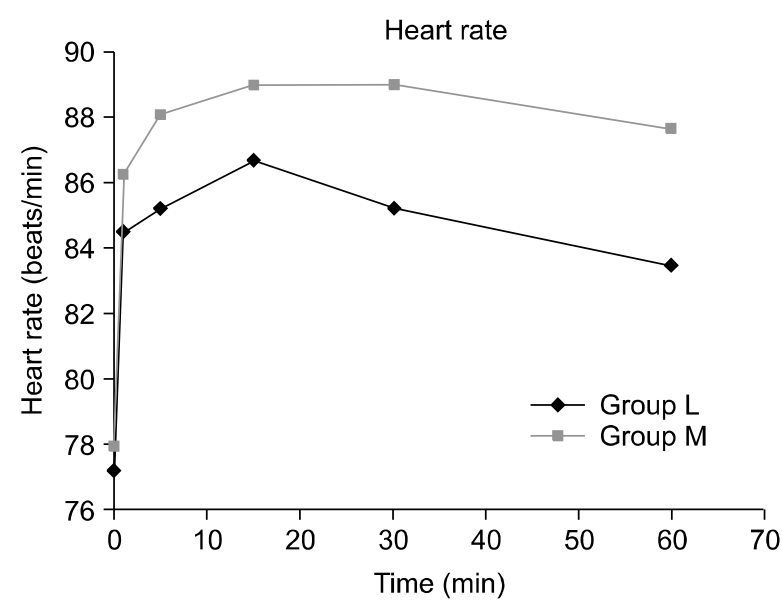

Fig. 4. Changes in heart rate between groups $L$ and $M$. Each bar represents the mean $\pm S D$. Group $L(n=50)$ received spinal anesthesia that consisted of hyperbaric lidocaine $(5 \%, 75 \mathrm{mg})$ and normal saline. Group M $(n=50)$ received spinal anesthesia that consisted of hyperbaric lidocaine $(5 \%, 75 \mathrm{mg})$ and meperidine $(0.2 \mathrm{mg} / \mathrm{kg})$. There were no significant differences between group $L$ and $M$. theless, the diastolic pressure at 5, 15, 30, and 60 minutes after the spinal anesthesia significantly decreased compared to the baseline in both groups $(P<0.05)$ (Fig. 3). There were six patients in group $L$ and seven patients in group $M$ who were given ephedrine. No significant difference in heart rate between the two groups was observed (Fig. 4).

Significant debilitation of shivering was seen in parturients having received meperidine, and the results obtained

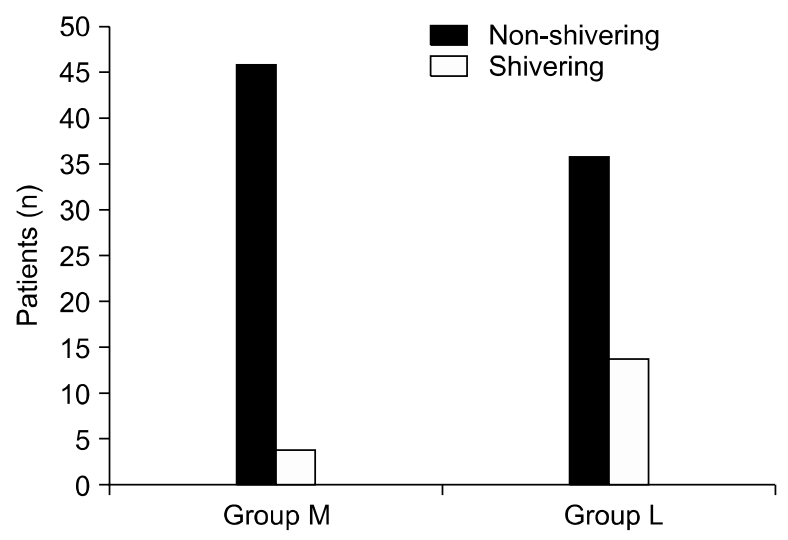

Fig. 5. The incidence of shivering. The incidence of shivering was significantly lower in group $M$ than in group $\mathrm{L}(P<0.05)$.

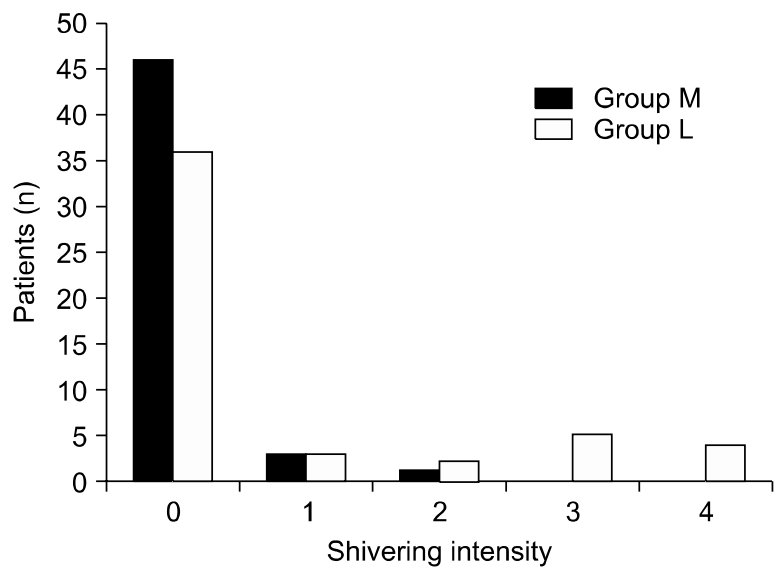

Fig. 6. The intensity of shivering for each patient; 0 , no shivering; 1 , peripheral, piloerection vasoconstriction, or both are present but no visible shivering; 2 , muscular activity in only one muscle group; 3 , muscular activity in more than one muscle group but no generalized shivering (moderate muscular activity); 4, shivering involving the whole body (violent muscular activity). There were significant differences in the intensity of shivering between groups $L$ and $M$ $(P<0.05)$. 
Table 2. Adverse Effects of the Two Study Groups During the Whole Time of the Study Period

\begin{tabular}{lcll}
\multicolumn{1}{c}{ Variable } & $L^{*}(\%)$ & $M^{*}(\%)$ & $P$ value \\
Nausea $^{\dagger}$ & 0 & $4(8.0)$ & NS \\
Vomiting $^{\dagger}$ & 0 & $5(10.0 \%)$ & NS \\
Hypotension $^{\dagger}$ & $6(12.0 \%)$ & $7(14.0 \%)$ & NS \\
Bradycardia $^{\dagger}$ & 0 & 0 & NS \\
Tachycardia $^{\dagger}$ & 0 & 0 & NS \\
Pruritus $^{\dagger}$ & 0 & 0 & NS
\end{tabular}

NS: not significant. ${ }^{\star}$ L: control group, M: case group. ${ }^{\dagger}$ Frequency (percentage) is reported.

were statistically significant (Fig. 5, $P=0.04$ ). According to the grade of shivering, of the four parturients in the M group who experienced shivering, three were Grade 1, one was Grade 2 and no parturients were Grades 3 and 4. Of the 14 parturients in the $\mathrm{L}$ group who presented with shivering, three were Grade 1, two were Grade 2, five were Grade 3, and four were Grade 4 (Fig. 6).

There were no significant differences in nausea and vomiting between the meperidine group and the controls (Table 2, $P>0.05$ ). Clonidine was used as a rescue for shivering treatment for 4 parturients in the meperidine group and 14 parturients in the controls. The apgar scores were similar between the two study groups $(P>0.05)$.

\section{DISCUSSION}

According to the data, adding a small dose of meperidine $(0.2 \mathrm{mg} / \mathrm{kg})$ to the intrathecal mixture of anesthesia reduces the intensity of shivering in an obstetric population undergoing spinal anesthesia for cesarean section. And the use of intrathecal meperidine at the doses used in this study does not significantly increase unwanted adverse effects such as nausea, vomiting, hypotension, bradycardia, tachycardia, and pruritus.

Spinal anesthesia is widely used for cesarean section. Spinal anesthesia causes well established side effects such as headache, dysuria, nausea, and vomiting, for which treatment has been considerably examined to date. Shivering is another side effect which is defined as an involuntary movement of muscles that can cause discomfort in patients. In some cases, postoperative pain may stimulate the development of shivering [19]. For the safety of patients, perioperative monitoring of vital signs such as body temperature is necessary. Particularly, the manage- ment of body temperature following aneasthesia is closely related to patient status and postoperative outcome. The perioperative occurrence of shivering may increase the intracranial pressure [20], intraocular pressure [21], oxygen consumption and complicate the use of a monitor [22] and increase the synthesis of carbon dioxide by three-fold. Therefore, an increase in metabolic demand induces difficulties in patients with intrapulmonary compartments, limited pulmonary capacity, and a fixed cardiac output [23].

The mechanism by which shivering develops is still unclear. The etiology of shivering is supposed to be heat loss throughout the anesthesia and surgery. However, there is a critical dispute encompassing the incidence of hypothermia due to heat loss. Jones and McLaren [24] showed that the occurrence of postoperative shivering was related to the decrease in body temperature which is measured through the esophagus. However, in contrast to the reports of Jones and McLaren, Pflug et al. [25] reported no significant differences in core temperature between both groups of patients who experienced shivering and those who did not. In our study, no significant difference in core temperature was observed between the study groups.

Several hypotheses have been stated to describe the incidence of postoperative shivering [26,27] including the following: (1) loss of thermoregulatory vasoconstriction beneath the level of the anesthetized region, resulting in increased heat loss from the body surface due to the excessive thermogenesis; (2) redistribution of body or heat temperature, where core and peripheral temperatures are generated because of the redistribution of heat from the center to the periphery due to temperature differences; and (3) altered thermoregulation because of a mild increase in the sweating threshold and a small decrease in vasoconstriction.

As described previously, the etiology of shivering has not been completely elucidated, but it likely involves multiple etiologies. The treatment regimens for shivering are not fully established despite the various numbers of studies on shivering. Common treatment regimens for shivering conclude warming the body temperature, increasing the operating room temperature, and using drugs such as clonidine, meperidine, fentanyl, morphine, butophanol, malbuphine, doxapram, ketanserine, and taurine $[8,28]$.

Of the above mentioned treatment procedures, an intravenous infusion of meperidine is supposed to be the gold 
standard treatment. In comparison to other opioids, meperidine has a considerable antishivering effect; therefore, it is widely used to prevent and treat shivering [29]. Many studies have revealed that meperidine has a greater antishivering effect than a similar dose of fentanyl or morphine, with its affinity for $\mu$ - receptors. Likewise, it can be inferred that the greater antishivering effect of meperidine over other analgesic drugs is because of its affinity for the $\kappa$ - receptor. Up to now, it has not been fully elucidated by which mechanism meperidine mediates its antishivering effect. With regard to some clinical studies, meperidine slightly increases the threshold for sweating, significantly decreases the threshold for vasoconstriction, and reduces the threshold for shivering [30].

As described previously, an intravenous infusion of meperidine induces no pain despite its intramuscular infusion; therefore, it is very effective in the treatment and prevention of shivering. Unexpected side effects such as pruritis, bronchospasm, hypotension, bradycardia, respiratory insufficiency, nausea, and vomiting may be associated with an intravenous infusion of meperidine. Alternatively, an intrathecal infusion of meperidine can minimize these side effects [7]. Our data showed that the time to reach the highest block in the meperidine group was significantly lower than that of the controls; this effect may be proportionate to a low level dose of meperidine. Accordingly, these results show that meperidine added to hyperbaric lidocaine does not prolong the total anesthesia time.

However a single use of meperidine $(0.5-1.5 \mathrm{mg} / \mathrm{kg})$ for spinal anesthesia has a strong effect as a local anesthetic, but a higher dose of meperidine $(50 \mathrm{mg}$ ) is associated with respiratory depression in a dose-dependent manner [17]. In our study, due to the low dose of meperidine $(0.2 \mathrm{mg} / \mathrm{kg})$, respiratory depression did not occur. Moreover, there were no significant differences between the two studied groups in the comparison of the maximum height of sensory block.

In conclusion, the data of this study suggest that an intrathecal infusion of a low dose of meperidine included in a local anesthetic does not affect the height of the sensory block, prevents the occurrence of shivering, and minimizes the occurrence of unexpected side effects related to an intravenous infusion of meperidine.

\section{ACKNOWLEDGMENT}

The authors would like to acknowledge the authorities of Jahrom University of Medical Sciences for their financial support.

\section{REFERENCES}

1. Ciofolo MJ, Clergue F, Devilliers C, Ben Ammar M, Viars P. Changes in ventilation, oxygen uptake, and carbon dioxide output during recovery from isoflurane anesthesia. Anesthesiology 1989; 70: 737-41.

2. Kurz A, Sessler DI, Schroeder M, Kurz M. Thermoregulatory response thresholds during spinal anesthesia. Anesth Analg 1993; 77: 721-6.

3. Han SY, Jin HC, Yang WD, Lee JH, Cho SH, Chae WS, et al. The effect of low-dose ketamine on post-caesarean delivery analgesia after spinal anesthesia. Korean J Pain 2013; 26: 270-6.

4. Matsukawa T, Sessler DI, Christensen R, Ozaki M, Schroeder M. Heat flow and distribution during epidural anesthesia. Anesthesiology 1995; 83: 961-7.

5. Lee C, Choi DH, Chae SU. Circadian effects on neural blockade of intrathecal hyperbaric bupivacaine. Korean $J$ Pain 2010; 23: 186-9.

6. Crowley LJ, Buggy DJ. Shivering and neuraxial anesthesia. Reg Anesth Pain Med 2008; 33: 241-52.

7. Han JW, Kang HS, Choi SK, Park SJ, Park HJ, Lim TH. Comparison of the effects of intrathecal fentanyl and meperidine on shivering after cesarean delivery under spinal anesthesia. Korean J Anesthesiol 2007; 52: 657-62.

8. Alfonsi P. Hongnat JM, Lebrault C, Chauvin M. The effects of pethidine, fentanyl and lignocaine on postanaesthetic shivering. Anaesthesia 1995; 50: 214-7.

9. Alfonsi P, Sessler DI, Du Manoir B, Levron JC, Le Moing JP, Chauvin M. The effects of meperidine and sufentanil on the shivering threshold in postoperative patients. Anesthesiology 1998; 89: 43-8.

10. Kurz M, Belani KG, Sessler DI, Kurz A, Larson MD, Schroeder $\mathrm{M}$, et al. Naloxone, meperidine, and shivering. Anesthesiology 1993; 79: 1193-201.

11. Delaunay L, Bonnet F, Liu N, Beydon L, Catoire P, Sessler DI. Clonidine comparably decreases the thermoregulatory thresholds for vasoconstriction and shivering in humans. Anesthesiology 1993; 79: 470-4.

12. Fukuda K. Intravenous opioid anesthetics. In: Miller's anesthesia. 6th ed. Edited by Miller RD. New York (NY), Elsevier Churchill Livingstone. 2005, pp 379-438.

13. Casey WF, Smith CE, Katz JM, O'Loughlin K, Weeks SK. Intravenous meperidine for control of shivering during caesarean section under epidural anaesthesia. Can J Anaesth 1988; 35: 128-33. 
14. Chen JC, Hsu SW, Hu LH, Hong YJ, Tsai PS, Lin TC, et al. Intrathecal meperidine attenuates shivering induced by spinal anesthesia. Ma Zui Xue Za Zhi 1993; 31: 19-24.

15. Roy JD, Girard M, Drolet P. Intrathecal meperidine decreases shivering during cesarean delivery under spinal anesthesia. Anesth Analg 2004; 98: 230-4.

16. Hong $J Y$, Lee $\mathbb{H}$. Comparison of the effects of intrathecal morphine and pethidine on shivering after Caesarean delivery under combined-spinal epidural anaesthesia. Anaesthesia 2005; 60: 1168-72.

17. Khan ZH, Zanjani AP, Makarem J, Samadi S. Antishivering effects of two different doses of intrathecal meperidine in caesarean section: a prospective randomised blinded study. Eur J Anaesthesiol 2011; 28: 202-6.

18. Crossley AW, Mahajan RP. The intensity of postoperative shivering is unrelated to axillary temperature. Anaesthesia 1994; 49: 205-7.

19. Horn EP, Schroeder F, Wilhelm S, Sessler DI, Standl T, von dem Busche K, et al. Postoperative pain facilitates nonthermoregulatory tremor. Anesthesiology 1999; 91: 979-84.

20. Mahajan RP, Grover VK, Sharma SL, Singh H. Intraocular pressure changes during muscular hyperactivity after general anesthesia. Anesthesiology 1987; 66: 419-21.

21. de Courcy JG. Artefactual 'hypotension' from shivering. Anaesthesia 1989; 44: 787-8.

22. Barker SJ, Shah NK. The effects of motion on the performance of pulse oximeters in volunteers (revised publication). Anesthesiology 1997; 86: 101-8.
23. Just B, Delva E, Camus Y, Lienhart A. Oxygen uptake during recovery following naloxone. Relationship with intraoperative heat loss. Anesthesiology 1992; 76: 60-4.

24. Jones HD, McLaren CA. Posoperative shvering and hypoxaemia after halothane, nitrous oxide and oxygen anaesthesia. $\mathrm{Br} J$ Anaesth 1965; 37: 35-41.

25. Pflug AE, Aasheim GM, Foster C, Martin RW. Prevention of post-anaesthesia shivering. Can Anaesth Soc J 1978; 25: 43-9.

26. Entezari Asl M, Isazadehfar K, Akhavanakbari G, Khoshbaten $M$. The effect of ondansetron in prevention of postoperative shivering after general anesthesia in gynecological surgery. Iran Red Crescent Med J 2012; 14: 316-7.

27. Shoar S, Esmaeili S, Khorgami Z, Naderan M, Shoar N. Efficacy of acupuncture in prevention of postoperative anaesthesia-related shivering. Acupunct Med 2013; 31 : $120-1$.

28. Horn EP, Werner C, Sessler DI, Steinfath M, Schulte am Esch J. Late intraoperative clonidine administration prevents postanesthetic shivering after total intravenous or volatile anesthesia. Anesth Analg 1997; 84: 613-7.

29. Stoelting RK, Hillier SC. Pharmacology \& physiology in anesthetic practice. 4th ed. Philadelphia (PA), Lippincott Williams \& Wilkins. 2006, p 864.

30. Kurz A, Ikeda T, Sessler DI, Larson MD, Bjorksten AR, Dechert $M$, et al. Meperidine decreases the shivering threshold twice as much as the vasoconstriction threshold. Anesthesiology 1997; 86: 1046-54. 